\title{
Role of Information Technology in heritage tourism: UNESCO World Heritage sites of Sri Lanka
}

\author{
$\mathbf{A}^{1}$ Abeysinghe, $\mathbf{A}^{2}$ Abeysinghe \\ ${ }^{1}$ Sri Lankan Aviation College \\ ${ }^{2}$ Software Engineer, DMS Electronics \\ arundathie81@yahoo.com
}

\begin{abstract}
Heritage and Information Technology (IT) may seem inconsistent at first. But IT has a significant role in heritage tourism. IT provides effective resources by which heritage tourism has evolved as a modern tool without harming its cultural and heritage identity. IT applications in heritage tourism include many disciplines of computer science from workflow to archaeological discovery as well as to scientific preparation. As such, there are diverse areas of cooperation as well as interaction at different levels. The use of IT as a tool in heritage tourism has paved the way for a three-dimensional $(3 D)$ model with the use of input data such as photos and scans. At the same time, computer graphics have created accurate visual creations. Several applications of IT in heritage tourism such as 3-D Modelling, database management of records, online reservation systems, Content Management and marketing via websites and social media can be identified. In this age of Information Technology and with the fast access of information, tourists at present require fast and accurate information and they have a thirst for knowledge about the destinations they visit. Hence, it is the duty of stakeholders of heritage tourism to provide the necessary information for tourists without harming the historical and cultural nature as well as the value of the site while using modern technology and preserving heritage tourism for future generations. This paper will focus on the role of IT in heritage tourism in UNESCO World Heritage sites in Sri Lanka for enriching visitor experiences at World Heritage sites in Sri Lanka during the travel cycle. At present, the majority of tourists local as well as foreign accumulate information about World Heritage sites, make reservations as well as buy services available in relevant sites using search engines.
\end{abstract}

Keywords: IT-based heritage tourism, World Heritage sites, use of AI in tourism, stakeholders of heritage tourism 


\section{Introduction}

As outlined in this research, IT has helped to uplift several domains in the context of heritage and tourism to present day baselines. Individuals, businesses and governments of all countries today use IT as an integral part of their routine to efficiently and productively provide services and gain revenue. IT is vehemently used in several sectors of heritage; identification, analysis of archaeological artifacts, content management, content sharing and marketing of tourism-related services. The research also outlines several innovations such as Artificial Intelligence (AI) based schema and sharing economy while highlighting several emerging trends in this domain. Additionally, the research provides several futuristic suggestions to further improve applications of IT and reach masses in the future while preserving current resources.

\section{Current applications of IT in Heritage and Tourism}

\section{3d Modelling}

3D modelling can be used as a technique for the conservation and experimentation of archaeological artifacts. With the introduction of 3D modelling software such as AutoCAD and Autodesk 3ds Max, IT has enabled archaeology and other tourismbased norms to create computer imagery of materials ranging from artifacts to entire buildings. With the use of this kind of software, it is very easy to create models of existing materials for preservation for the use of future generations as well as for materials that are not easily transportable. Several techniques have been devised recently under this paradigm. Key techniques include laser triangulation, Stereophotogrammetry, Structured light and Time of flight. The process of obtaining a 3D image includes steps of data registration, data integration, model conversion and visualization which can all be performed using 3D modelling software (Pieraccini, Guidi, \& Atzeni, 2001). Another key area of improvement recently is the use of 3D laser scanning of buildings as a process of preserving cultural heritage sites (Brizzi, Court, d'Andrea, Lastra, \& Sepio, 2006). 


\section{Database management of records}

After data is analyzed, it is equally important to store such data for future retrieval. The role of IT in this context has been significant with the adoption of database management systems. Database management systems not only help to create, save, update and delete data in a "database", but are the cornerstones in most content management websites today. For example, users today check which areas of a country have the most focus on tourism by analyzing data such as the weather, cost of travel, return on investment for the travel, etc. among a plethora of popular tourist destinations using mobile apps, forums and reviews. If database management systems were not used or were publicly restricted, there would be a minimal opportunity for tourists to obtain information about such sources.

\section{Online reservation systems}

A new trend among tourists has been to "book and travel" to a destination. With websites and mobile applications, key service providers in an online reservation such as TripAdvisor and Bookings.com enable tourists, easy access to information and reserve and travel. Coupled with these platforms are the reviews that travellers post. A recent survey found that $57 \%$ of young travellers use reviews for booking (eZee Technosys Pvt. Ltd, 2014).

\section{Content Management}

Content management in heritage tourism and archaeology is done using websites. Websites enable to easily present information and provide a platform upon which data can be exchanged between parties. Additionally, email and Instant Messaging schemes have soared word of mouth publicity about these tourism sites. A recent trend also involves developing mobile applications and content delivery to easily obtain information.

\section{Marketing via Websites and Social Media}

Marketing is another key area where IT has aided Heritage Tourism. For example, online advertising enables service providers in a particular domain to publicize their information globally. Before the introduction of IT-based systems, advertisements 
were only available to local communities and had less scope of reach. However, recent improvements in social media and content sharing networks have enabled to reach the masses within a short period at a low cost. For example, Facebook pages and Twitter profiles are used by popular tourist service providers, hotels and restaurants as a medium of promoting their content.

\section{Applications in archaeology}

IT has also enabled electronic data acquisition, data analysis and presentation in archaeological projects. With the use of computer-based systems, new archaeological instruments such as electronic Vernier callipers, video imaging systems and logging systems to store data have evolved. The data analysis stage involves using a database to store information and using data mining systems to analyze information pertaining to excavations. Computer Generated Imagery (CGI) and other modelling tools coupled with presentation software enable easy dissemination of information about findings from archaeological excavations. CGI tools are used as information dissemination tools for tourists at leading archaeologically significant sites in Sri Lanka.

\section{AI-Based Schema}

As stated in recent researches, (Puyol-Gruart, 2002) several techniques in the domain of AI can be applied to archaeology. Main schemes include KDD (Knowledge Discovery in Databases), VIM (Visual Information Management) and MAS (Multiagent systems). As stated earlier in this paper, the use of databases assists the efficient management of large archaeological facts that accumulate every day. However, databases in the context of KDD are not used just for CRUD (Create, Read, Update and Delete) of data, instead of towards a data mining system. In this process, data is preprocessed and such data goes through a data mining process to obtain patterns from pre-processed data. For example, figure 1 shows how fuzzy logic can be used, coupled with association rules to determine the era to which a particular artifact belonged. 


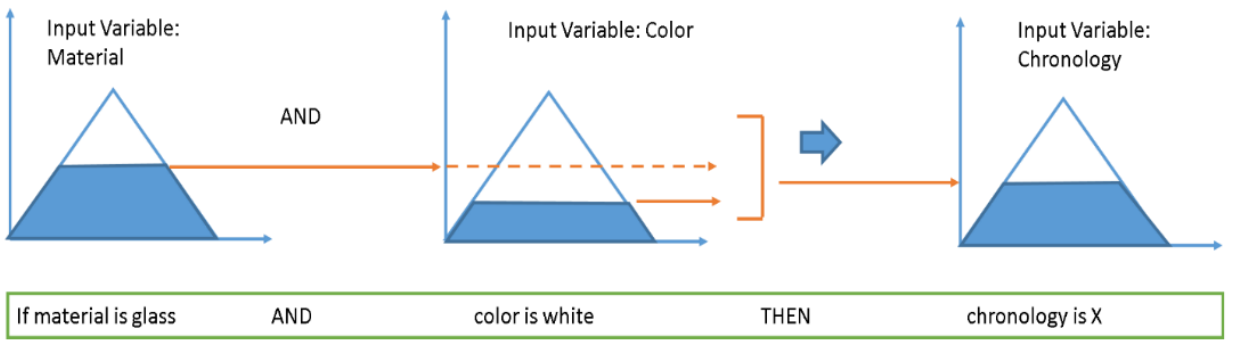

Figure 1: Use of fuzzy logic with association rules to detect the chronology of an artifact

Another key area of research in the domain of KDD is Bayesian networks. In Bayesian networks, the probability of a key event occurrence is evaluated in conjunction with another event(s) to identify an inference. This inference is either a conclusion or a collection of such inferences and they are used to conclude.

\section{The sharing economy}

In traditional markets, consumers own the product they purchase, a good or service. However, with sharing economy, peer-to-peer services share their goods or service as temporary endeavours. This is enabled by a platform which "sits" as the intermediary between the consumer and the supplier which forms the basis of the peer-to-peer model. The platform is often a customized website or sometimes a mobile application that acts as the gateway upon which both parties perform transactions. Examples of sharing economy practices include bike and carpooling and hotel rental services such as Airbnb.

With sharing economy, anyone can start their own business and provide services worldwide. This type of business provides opportunities to both local and overseas services and customers have opportunities to obtain services from a trusted provider than from unreliable sources. It enables a common platform upon which transactions can be made. For example, a tourist can reserve a villa in Thailand or a hotel in Hong Kong with Airbnb. A tourist does not have to visit hundreds of country-specific sites to view and book before travelling. All financial transactions are also controlled by one centralized account for the user which in essence increases usability and personalization of services (Juul, 2017). 


\section{Emerging trends in IT-based Heritage Tourism}

\section{e-Heritage}

One of the emerging trends in heritage tourism is e-Heritage. With e-Heritage, each country opts to build a common portal upon which all Heritage Tourism information will be stored and disseminated. For example ICTA (Information and Communication Technology Agency), Sri Lanka has already initiated an 'e-Heritage' project (ICTA, 2017), a search that allows users to filter results by destination, category, building type, address etc. The primary advantage of such an approach is that a potential visitor can search an entire country based on a keyword and some data with a filter criterion. This reduces the time consuming and inefficient task of searching through several websites, forums, reviews, blogs and then baselining a common understanding upon which the travel would be based. Additionally, the credibility of information can be guaranteed as the information will often be managed by the government of a country or a highly trusted institution.

\section{Tourism Entrepreneurship}

These new IT-related ventures in tourism create employment opportunities for local communities. As a result of these services, tourist service providers have been able to breach the monopoly, "business-oriented" environments had over the years. The hospitality industry is divided, though not equally between a market of local communities and a market of niche business organizations.

As pinpointed by this study, several new trends can be seen to improve the outcome of this process. For example, many tourism-based websites today involve a translation scheme such as Google Translate to translate website content to a specific language. At the same time, websites today involve using local font typefaces in typing for communities who lack English proficiency. These methods improve customer satisfaction by diminishing cultural and language proficiency barriers in communication. Another trend has been cross-platform data availability and moderation. For example, when a tourist enters his/her details on a website (personal information) and books a hotel, he/she can view or edit the same information using a 
mobile application developed for smartphones. This increases customer flow to the tourism market and creates new entrepreneurship in Heritage Tourism.

\section{Virtual Tours}

Several companies have improved their presentation of services and also about heritage tourist sites in the form of virtual tours. However, several improvements can be made in this domain to improve the tourist experience. For example, current virtual tours are limited often to a flash video on a website or a video about services and attractions at public places. The majority of present-day travellers have no experience of virtual tours when they visit the aforementioned sites, although they get a firsthand view of the tour. So, virtual tours are important to self-explore a cultural site or service of a service provider in the domain of Heritage Tourism. This can involve key places they should visit which can be displayed on computer screens which they can access by pressing a button and view information about a place or service. Additionally, they can drag a pointer in the screen to view $360^{\circ}$ view of the place or panorama of the place and provides ease of use in gathering information on how they should visit the particular site and what they can see in a destination or how they can use the service of a service provider rather than reading booklets or pamphlets about places which are typically available at these destinations. For example, for tourists, virtual tours are available in the World Heritage sites of Dambulla Cave Temple and Galle (Thobias).

\section{Conclusion}

In conclusion, IT in heritage sites plays a significant role and in the future, it will be an essential tool as tourists, (local and foreign) will need to access information fast and accurately within a short period. As tourists are interested in knowledge about the site they will be visiting, Sri Lanka Tourism Development Authority and Tourism Bureau Promotion Bureau can play a huge role in this endeavour by promoting Sri Lanka as a destination with UNESCO World Heritage sites by displaying virtual tours, online brochures, pamphlets as well as video and audio clips in several foreign languages including English for the benefit of foreigners who will be visiting Sri Lanka. This type of endeavour will also benefit travel agencies worldwide as they can 
promote these sites and Sri Lanka as a World Heritage-listed tourist destination worldwide and attract more tourists with the use of advances in IT. The research believes that recommendations as outlined under futuristic suggestions will ensure further expansion of the applications of IT in Heritage Tourism.

\section{References}

3D digitizing of cultural heritage2001Journal of Cultural Heritage 63-70

3D Laser Scanning as a Tool for Conservation: The Experiences of the Herculaneum Conservation Project 2006The 7th International Symposium on Virtual Reality, Archaeology and Cultural Heritage VAST (2006)1-7GoslarEurographics Association

Computer Science, Artificial Intelligence and Archaeology2002Computer Applications \& Quantitative Methods in Archeaology1-7CreteComputer Applications \& Quantitative Methods in Archaeology

Dambulla Cave Temple - Sri Lanka - 360 degree virtual reality tour.

Experiment of virtual space distance education system using the objects of cultural heritage1999Proceedings IEEE International Conference on Multimedia Computing and SystemsFlorenceIEEE

eZee Technosys Pvt. Ltd2014Survey: What Travelers Are Looking For In Online Reviews

ICTAICTA and Department of National Museums launch Sri Lanka Museums Mobile App

Tourism and the sharing economy

Juul, Maria. The Sharing Economy and Tourism. 1st ed. European Parliament, 2017. 